\title{
Interannual variations of tropical upper tropospheric humidity and tropical rainy-region SST: Comparisons between models, reanalyses, and observations
}

\author{
Huiwen Chuang, ${ }^{1}$ Xianglei Huang, ${ }^{1}$ and Kenneth Minschwaner ${ }^{2}$ \\ Received 16 March 2010; revised 3 June 2010; accepted 24 July 2010; published 11 November 2010.
}

[1] Tropical deep convection plays a key role in the vertical transport of moisture to the upper troposphere. Here we investigate relations between the interannual anomalies of the sea surface temperature (SST) in the tropical strong precipitation regions (rainy-region SST) and tropical upper tropospheric humidity (UTH), as seen from the ECMWF ERA-40 and ERA-interim reanalyses, AIRS observations, and four global climate model (GCM) simulations from the IPCC AR4 archive. Important differences are found between the two reanalyses and between models and observations/reanalyses. The mean correlation coefficients between interannual anomalies of UTH (250-400 mb) and rainy-region SST are 0.46 for the ECMWF ERA-40 but 0.86 for ERA-interim and 0.87 for the 6-year AIRS data, which are all higher than their counterparts when the tropical-mean SST anomalies are used instead. All GCMs exhibit systematically stronger correlations $(\sim 0.95)$ for both types of SST anomalies. Fractional changes of UTH anomalies with respect to the two types of SST anomalies are also examined. Using modeled and reanalyses tropical temperature profiles as input, an idealizing model that assumes deep convection for the only source of water vapor is used to compute the UTH variations. Except for the case of ECMWF ERA-40, the idealized model reasonably reproduces the UTH profiles at 250 and $300 \mathrm{mb}$ for all other cases, corroborating the dominate control of deep convection on the humidity in these layers. The UTH at $200 \mathrm{mb}$ derived from the idealized model is 1.5 to 2 times more humid than those from the GCMs and reanalyses, suggesting the importance of drying mechanisms at this level and probably above. Possible causes for the outlier behavior of ERA-40 are also discussed.

Citation: Chuang, H., X. Huang, and K. Minschwaner (2010), Interannual variations of tropical upper tropospheric humidity and tropical rainy-region SST: Comparisons between models, reanalyses, and observations, J. Geophys. Res., 115, D21125, doi:10.1029/2010JD014205.

\section{Introduction}

[2] Owing to its roles in radiation, dynamics, cloud microphysics, and the complex interactions between these processes, water vapor lies in the heart of projecting future climate change. Water vapor feedback is the most important positive feedback to amplify the surface warming caused by increases of greenhouse gases in the atmosphere [Held and Soden, 2000; Bony et al., 2006; Soden and Held, 2006]. Particularly, owing to its important role in regulating the radiation budget and close connection to tropical deep convection, the tropical upper tropospheric humidity (UTH) has been a focus in climate research since the 1990s [Lindzen, 1990; Soden and Bretherton, 1994; Soden and Fu, 1995;

\footnotetext{
${ }^{1}$ Department of Atmospheric, Oceanic and Space Sciences, University of Michigan, Ann Arbor, Michigan, USA.

${ }^{2}$ Department of Physics, New Mexico Institute of Mining and Technology, Socorro, New Mexico, USA.

Copyright 2010 by the American Geophysical Union. 0148-0227/10/2010JD014205
}

Sherwood, 1996; Pierrehumbert and Roca, 1998; Dessler and Sherwood, 2000; Sherwood and Dessler, 2003; Soden et al., 2005; Sherwood et al., 2006; Su et al., 2006; John and Soden, 2006; Dessler et al., 2008; Sherwood et al., 2010]. The major source of tropical UTH is tropical deep convection [Houze and Betts, 1981; Held and Soden, 2000] while its large-scale distribution is influenced by moisture advection and diffusion, as well as condensation [Betts and Albrecht, 1987; Sun and Lindzen, 1993; Udelhofen and Hartmann, 1995; Sherwood, 1996; Pierrehumbert, 1998; Pierrehumbert and Roca, 1998; Dessler and Sherwood, 2000]. Tropical deep convection transports moisture upward and injects it to the upper troposphere. The deep convection also plays an indispensable role in maintaining a nearly moist, adiabatic profile for the entire tropical troposphere [Stone and Carlson, 1979; Xu and Emanuel, 1989; Wallace, 1992]. From this point of view, deep convection is the venue from which the upper troposphere can directly "communicate" with the surface. For the same reason, the surface temperature over nonconvective regions has no such 
direct connection with upper tropospheric temperature, or with the UTH. Therefore, the tropical mean UTH variations could be expected to correlate more closely with the variations of surface temperature in deep-convection regions rather than those in large-scale subsidence (nonconvective) regions.

[3] Many previous studies [Sun and Held, 1996; Sun et al., 2001] about the tropical UTH and upper-tropospheric temperature employed the tropical-mean sea surface temperature (SST) variations instead of the SST variations over deepconvection regions. Sobel et al. [2002] explained, from a statistical point of view, the coincidence of obtaining similar interannual variations from different ways of sampling the tropical SST. In the same study it has been argued that, for large ENSO events, the variations of tropical-mean SST and SST over the deep-convection regions could be indeed significantly different. There also have been studies that used different convective indices such as SST threshold, OLR (outgoing longwave radiation), precipitation, and high-cloud fraction to filter SST and analyzed relations between such filtered SST and upper tropospheric properties. For example, Minschwaner and Dessler [2004] (hereafter MD04) used monthly mean OLR less than $250 \mathrm{Wm}^{-2}$ as a filter to obtain monthly mean SST over the deep-convection region and then studied its interannual variation with UTH anomalies observed from UARS MLS (Upper Atmosphere Research Satellite, Microwave Lime Sounder). Convective-region SST has also been approximated in some studies [Lindzen et al., 2001; Hartmann and Michelsen, 2002; Su et al., 2008] by weighting SST by cloud fraction. Kubota and Terao [2004] on the other hand, used daily precipitation rate $(>6 \mathrm{~mm}$ day $^{-1}$ ) as a convective index to compile SST only over such strong precipitating regions (hereafter, rainy-region SST) and then examined decadal variability of such rainy-region SST.

[4] Relationships between tropical mean water vapor and temperature over the interannual timescale were first studied by Sun and Held [1996]. They found large discrepancies between the GFDL GCM, and radiosonde observations: Modeled correlations being much larger than observed. When the same analysis was performed to GCM output archived for Atmospheric Model Intercomprison Project (AMIP) [Sun et al., 2001], the discrepancies were essentially the same even though the models were significantly different from each other in many aspects. Huang et al. [2005] showed inconsistent interannual covariability of tropical temperature and humidity between two reanalyses (ECMWF ERA-40 and NCEP reanalyses), the GFDL AM2 model, and HIRS observations from the NOAA satellite. A discrepancy in the water vapor field in ERA-40 and NCEP reanalysis was also found by Chen et al. [2008]. In another words, such modelobservation discrepancies remain unchanged in fifteen years, although both models and observations themselves have been improved substantially.

[5] In this study, we examine correlations between interannual anomalies of tropical UTH and rainy-region SST (as an index of convection-region SST) in the observations, reanalyses, and GCM simulations. Given the fact that the area covered by the deep convection could vary significantly at intraseasonal and even shorter timescales (e.g., due to monsoon onset or tropical intraseasonal oscillation), it would be meaningful to construct a rainy-region SST based on precipitation data at daily or pentad timescales, instead of monthly timescales. Then interannual rainy-region SST anomalies can be obtained from compilations of such dailyor pentad-resolution rainy-region SST. Such anomalies then can be correlated with the tropical UTH anomalies. The study uses newly available reanalysis (ECMWF ERAinterim), satellite observations (AIRS humidity profiles), and IPCC AR4 GCM simulations to revisit the discrepancies mentioned in the previous paragraph, with a focus on the influence of rainy-region SST on the UTH anomalies. An idealized equilibrium model that has convection as the sole source of tropical UTH will also be used to further understand such control of UTH variation by the deep convection as seen from the reanalyses and GCM simulations.

[6] The sections of this paper are organized as follows. Datasets and methodology are presented in section 2 . Section 3 describes the results from analyzing reanalyses, observations, and GCM simulations. Section 4 discusses the tropical UTH profiles computed from the idealized equilibrium model and comparisons with those produced from reanalyses and GCM simulations. Conclusion and discussion are given in section 5 .

\section{Data and Method}

\subsection{Datasets and Definition of Rainy-Region SST}

[7] Monthly mean specific humidity from Atmospheric Infrared Sounder (AIRS) [Fetzer et al., 2006] and from two ECMWF reanalysis products, ERA-40 [Uppala et al., 2005] and ERA-interim [Simmons et al., 2006; Uppala et al., 2008], are analyzed in this study. Compared to the ERA40 , noteworthy advances in ERA-interim data assimilation system are (1) 12-hourly 4-D var instead of 6-hourly 3-D var; (2) higher horizontal resolution (T255 versus T159, i.e., $\sim 75$ $\mathrm{km}$ versus $125 \mathrm{~km}$ ); (3) a new humidity analysis algorithm and improved model physics; (4) variational bias correction of satellite radiance data instead of the static bias correction in ERA-40, as well as other improvements in bias handling. More detailed improvements and impacts on data assimilation can be found by Uppala et al. [2008]. As a result, its assimilated UTH properties are noticeably different than from the ERA-40 model, which shall be seen in section 3. Observational precipitation data are taken from the pentadresolution GPCP (Global Precipitation Climatology Project) data [Huffman et al., 2001; Adler et al., 2003; Xie et al., 2003]. Pentad-resolution rainy-region SST is then obtained as follows: first the monthly NOAA Optimum Interpolation (OI) SSTs [Reynolds and Marsico, 1993; Reynolds et al., 2002] are temporally interpolated to the mid-point of each five-day period used in the GPCP data, then rainyregion SST is defined as SST over regions with GPCP precipitation higher than $6 \mathrm{~mm} /$ day. Such a threshold, which encompasses the $16.54 \%$ high end of probability distribution function (PDF) of GPCP precipitation in the tropics, has been used in previous studies as well [Sobel et al., 2002; Kubota and Terao, 2004]. The overall results are not sensitive to the moderate change of the choice of such $6 \mathrm{~mm} /$ day rain threshold. Other relevant details of observational and reanalysis data are summarized in Table 1.

[8] Figure 1a shows the time series of fractional area defined as rainy region in this way over the entire tropics $\left(30^{\circ} \mathrm{N}-30^{\circ} \mathrm{S}\right)$ and over the inner tropics $\left(15^{\circ} \mathrm{S}-15^{\circ} \mathrm{N}\right)$, 
Table 1. Summary of Observational and Reanalysis Data Used in This Study

\begin{tabular}{llccc}
\hline \multicolumn{1}{c}{ Data Sources } & \multicolumn{1}{c}{ Variables } & Horizontal Resolution & Time Period Analyzed Here & Focused Area \\
\hline AIRS L3 monthly means & Specific humidity & $1^{\circ} \times 1^{\circ}$ & $2003.01-2008.12$ & $30^{\circ} \mathrm{S}-30^{\circ} \mathrm{N}$ \\
NOAA OI v2 SST & SST & $1^{\circ} \times 1^{\circ}$ & $1982.01-2008.12$ & $15^{\circ} \mathrm{S}-15^{\circ} \mathrm{N}$ \\
GPCP v1.0 & Precipitation & $2.5^{\circ} \times 2.5^{\circ}$ & $1982.01-2008.12$ & $15^{\circ} \mathrm{S}-15^{\circ} \mathrm{N}$ \\
ECMWF ERA-40 & Specific humidity & $2.5^{\circ} \times 2.5^{\circ}$ & $1982.01-2001.12$ & $30^{\circ} \mathrm{S}-30^{\circ} \mathrm{N}$ \\
ECMWF ERA-interim & Specific humidity and SST & $1.5^{\circ} \times 1.5^{\circ}$ & $1989.01-2008.12$ & $30^{\circ} \mathrm{S}-30^{\circ} \mathrm{N}$ \\
\hline
\end{tabular}

respectively. The rainy region occupies $14.91 \%$ of the entire tropics and $20.37 \%$ of the inner tropics on average.

[9] For comparison, monthly mean UTH and SST as well as daily precipitation from the 20th-century run $(20 \mathrm{C} 3 \mathrm{~m})$ of four IPCC-AR4 coupled GCMs (GFDL-CM2.0, ECHAM5, MRI-CGCM2.3.2, and NCAR-CCSM3) are analyzed. The relevant details of the four GCMs are listed in Table 2. The four GCMs used here have different native vertical resolutions even though the archives at PCMDI were provided at the IPCC AR4 mandatory levels. The number of layers in the upper troposphere (e.g., $100-400 \mathrm{mb}$ ) varies from five to ten, providing enough vertical levels for interpolating onto the IPCC AR4 levels. Ingram [2002] showed that the UT water vapor variation and feedback are not sensitive to the vertical resolution of such GCMs or even higher ones.

[10] Given that the large-scale SST varies smoothly with the time, that no daily SST observations over the entire tropics are available for the period of 1980-1999, and that
GCM simulations usually are done with SST interpolated from monthly mean SST, we adopt here the same approach and linearly interpolate monthly SST to daily resolution. Precipitation simulated by a GCM could be significantly different from observed in both the magnitude and in the PDF. Therefore, for each GCM, we first compute the PDF of simulated daily precipitation over the entire tropics then define the rainy regions on any given day as being regions with daily precipitation falling into the $16.54 \%$ high end of the PDF, the same PDF criterion used in the observational analysis.

\subsection{Data Analysis}

[11] In this study, we focus on the interannual variation of UTH profiles over the entire tropics and its relation to the interannual variation of rainy-region SST in the inner tropics. Monthly mean rainy-region SST is obtained from pentad (for observations and reanalyses) or daily (for GCM
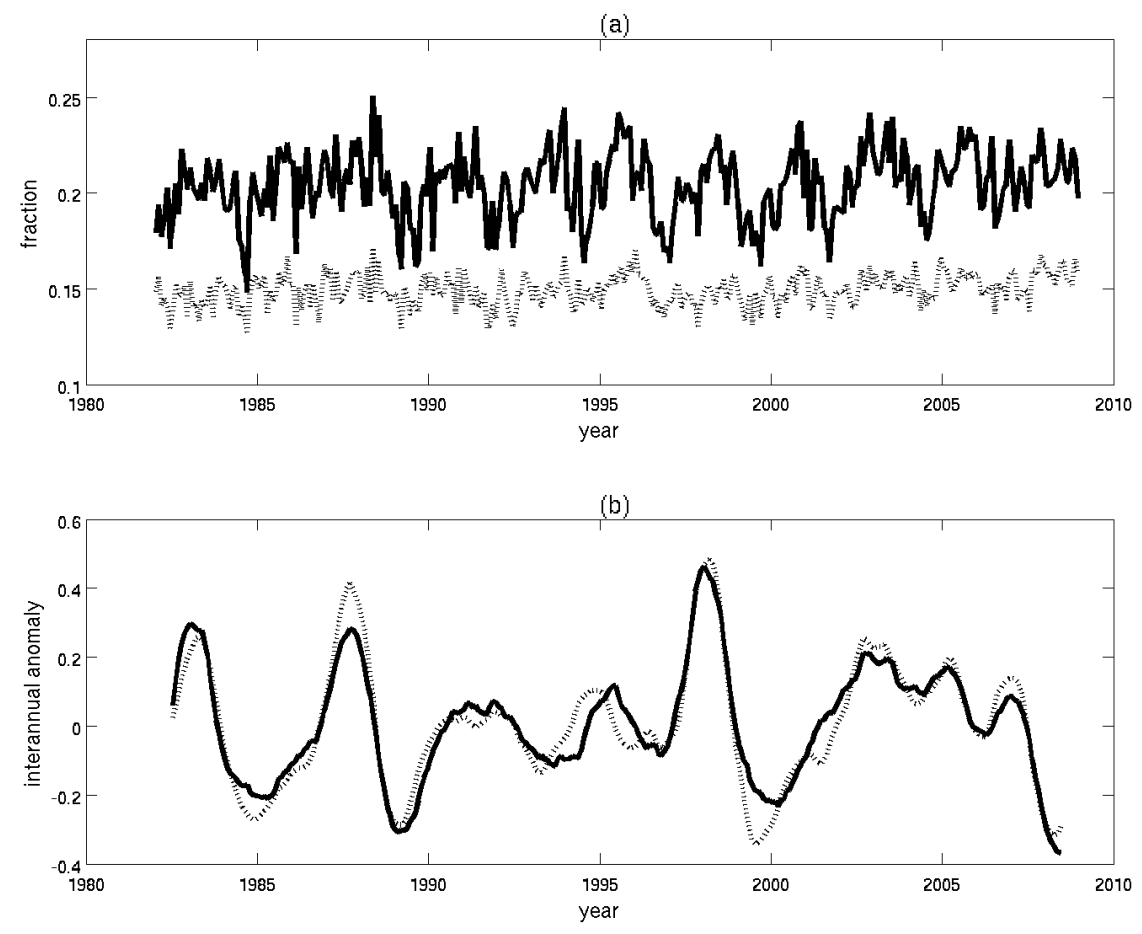

Figure 1. (a) Dotted gray curve is the time series of the percentage of tropical area $\left(30^{\circ} \mathrm{S}-30^{\circ} \mathrm{N}\right)$ with GPCP pentad-resolution precipitation larger than $6 \mathrm{~mm} / \mathrm{d}$. Solid curve is same except for the inner tropics $\left(15^{\circ} \mathrm{S}-15^{\circ} \mathrm{N}\right)$. (b) Dotted line is the interannual anomalies of observed NOAA SST averaged over the entire inner tropics. Solid line is the interannual anomalies of observed rainy-region SST in the inner tropics. Definition of the rainy-region SST and method to compute the interannual anomaly can be found in section 2 of the context. 
Table 2. Summary of the Four GCM Simulations (the 20th Century Run) Used in This Study ${ }^{\mathrm{a}}$

\begin{tabular}{lcccc}
\hline \multicolumn{1}{c}{ GCMs } & Horizontal Resolution & Time Period & Convection Scheme & Dynamic Core \\
\hline NCAR-CCSM3 & T85 $\left(\sim 1.4^{\circ}\right)$ & $1980.01-1999.12$ & Zhang and McFarlane [1995] & Spectrum \\
GFDL-CM2.0 & $2.0^{\circ} \times 2.5^{\circ}$ & $1980.01-1999.12$ & $\begin{array}{c}\text { Relaxed Arakawa-Schubert } \\
\text { [Moorthi and Suarez, 1992] }\end{array}$ & $\begin{array}{c}\text { Finite difference (Horizontal) } \\
\text { and finite volume (vertical) }\end{array}$ \\
ECHAM5 (Germany) & T63 $\left(\sim 1.875^{\circ}\right)$ & $1980.01-1999.12$ & $\begin{array}{c}\text { Tiedtke [1989] and Nordeng [1994] } \\
\text { Spectrum }\end{array}$ & $\begin{array}{l}\text { Spectrum } \\
\text { MRI-CGCM2.3.2 (Japan) }\end{array}$ \\
& T42 $\left(\sim 2.8^{\circ}\right)$ & $1980.01-1999.12$ & $\begin{array}{c}\text { Prognostic Arakawa-Schubert } \\
\text { [Randall and Pan, 1993] }\end{array}$ & \\
\hline
\end{tabular}

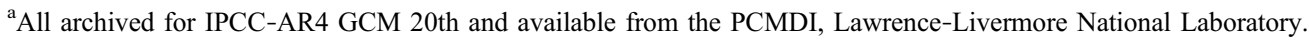

simulations) rainy-region SST interpolated from monthly mean SST as we describe in the previous paragraph. Then interannual anomalies are computed from the monthly mean rainy-region SST and UTH profiles in the same way as Huang et al. [2005]: a linear trend is first removed by regression, next the mean seasonal cycle is computed and subtracted from the data, and finally a 13-month moving average is applied to the data to obtain the interannual anomalies (for brevity, hereafter interannual anomalies and anomalies are used interchangeably.). The interannual anomalies of SST and rainy-region SST obtained in this way are shown in Figure 1b. As shown in previous studies such as Sobel et al. [2002], the two anomalies resemble each other to a large extent although the rainy-region SST anomalies generally have smaller amplitude than the tropical mean SST anomalies.

[12] The statistical significances of correlations between the two time series of interannual anomalies are assessed with a Monte-Carlo isospectrum method [Camp et al., 2003]. The method first generates 100,000 surrogate time series with power spectra identical to one of the two time series but randomized phases, and then the correlation with the other time series is computed for each surrogate time series. By doing so, a probability of obtaining a correlation coefficient as large as any specified value can be estimated in a double-sided test.

\subsection{Idealized Model}

[13] An idealized, single-column steady-state radiativeconvective model is used here to further understand results from data analysis. A detailed description of the model can be found in MD04. The model describes the balance between adiabatic warming and clear-sky radiative cooling outside the cores of deep convection as well as the conservation of humidity through detrainment process, assuming negligible contribution from evaporation of condensates. Specifically, it calculates the downward air mass flux (M) by

$$
M=\frac{Q_{R}}{C_{p}\left(\frac{d T}{d z}+\Gamma_{d}\right)}
$$

where $C_{p}$ is the heat capacity of dry air, $T$ is the temperature, $z$ is the altitude, $\Gamma_{\mathrm{d}}$ is the dry-adiabatic lapse rate, and $Q_{R}$ is the clear-sky radiative cooling rate,

$$
Q_{R} \cong Q_{R}(T, q)
$$

where $q$ is the specific humidity. In this study $Q_{R}$ is computed from the stand-alone NCAR CCM3 radiation column model [Kiehl et al., 1998] for any given $(T, q)$ profiles.
[14] The model further assumes that convection detrainment is the sole source of tropical UTH and evaporation of condensate during detrainment is negligible. Then the vertical convergence of the upper-tropospheric downward mass flux should be compensated by the detrainment from the deep convection, i.e.,

$$
\frac{d M}{d z}\left[q-q^{*}(T)\right]=-M \frac{d q}{d z}
$$

where $\mathrm{q}^{*}$ is saturation specific humidity.

[15] In this study we specify the temperature profile to be either the tropical-mean $\left(30^{\circ} \mathrm{N}-30^{\circ} \mathrm{S}\right)$ profiles from a GCM simulation or that from a reanalysis product. The three equations described above are solved simultaneously by iteration to obtain steady-state solutions to $M, q$, and $Q_{R}$. Hereafter, we denote the humidity profiles obtained from this simple model as $q_{D C}$, where the subscript "DC" is used to emphasize that the only source of $q$ in this model is deep convection.

\section{Data Analysis Results}

[16] The correlation coefficients between the interannual anomalies of tropical-mean UTH profiles (from $400 \mathrm{mb}$ to $150 \mathrm{mb}$ ) and that of rainy-region SST are shown in Figure 2. For comparison, the correlations with SST interannual anomalies averaged over the entire inner tropics are shown in the same plot. For ERA-40 reanalysis, when mean SST is used, only correlations at $200 \mathrm{mb}$ and $150 \mathrm{mb}$ are statistically significant. When rainy-region SST is used, the correlation is noticeably improved from $\sim 0.4$ to $\sim 0.5$ and such correlation is statistically significant from $400 \mathrm{mb}$ to $150 \mathrm{mb}$. For AIRS, the correlation coefficients between mean SST and UTH anomalies are $\sim 0.80-0.90$, much higher than those of ERA-40. When rainy-region SST is used instead of mean SST, the correlation is slightly improved by $\sim 2.0 \%$ for $200-400 \mathrm{mb}$ but reduced by $4.75 \%$ at $150 \mathrm{mb}$. Note such slight increase or decrease of correlation is within the uncertainty due to the short time period of AIRS data (please see the next paragraph for an estimate for such uncertainty) and AIRS humidity retrieval is less confident at levels above $200 \mathrm{mb}$ [Fetzer et al., 2006]. For the ERAinterim reanalysis, its correlation coefficients are close to those of AIRS (a cautionary note here is that the degrees of freedom of six years of AIRS data are significantly different from those of twenty years of ERA-interim data). When rainy-region SST is used, slight to moderate improvements can be seen for $400250 \mathrm{mb}$, largest of which is $11.3 \%$ at $350 \mathrm{mb}$. Similar to the case of AIRS, the correlation is reduced slightly above $250 \mathrm{mb}$. 


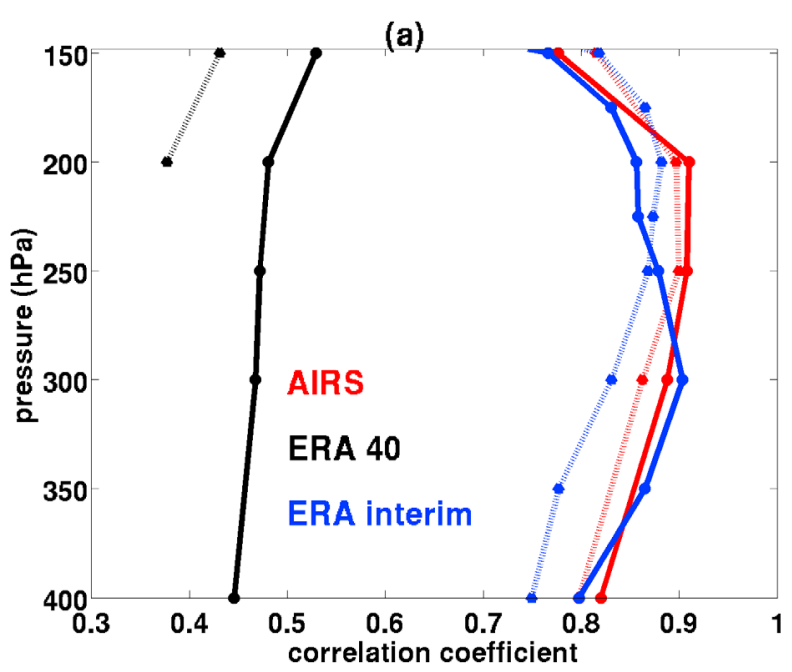

(b)

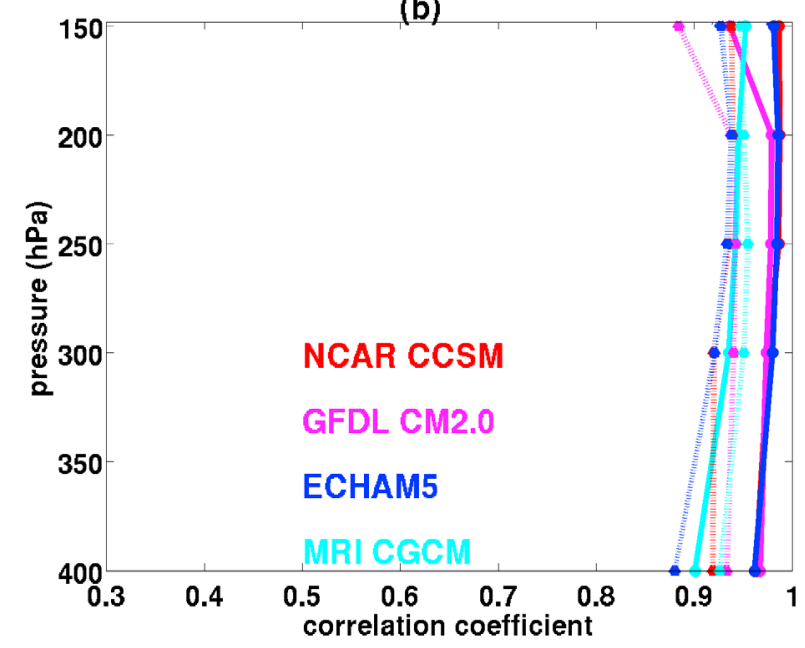

Figure 2. (a) Solid (dash) lines are correlation coefficients between interannual anomalies of tropical mean specific humidity and those of inner-tropical $\left(15^{\circ} \mathrm{S}-15^{\circ} \mathrm{N}\right)$ rainyregion SST (inner-tropical mean SST). Only statistically significant correlations are plotted. Results from AIRS data are in red, ERA-40 in black, and ERA-interim in blue. (b) Same as Figure 2a except for four GCM results.

[17] It has been noted before that the interannual anomalies of ERA-40 UTH are different from those of NCEP reanalysis and satellite measurements [Huang et al., 2005]. The discrepancies between ERA-40 and ERA-interim are most likely due to the changes implemented in ERA-interim that are related to moist physics and elimination of volcano contamination in the satellite radiances assimilated into the reanalysis. The correlations of AIRS data are derived from six years of data, in contrast to the twenty years of data used in ERA-40 and ERA-interim. To assess the influence of such limited period on the derived correlations, we calculated the correlations for six consecutive years of ERAinterim data and compared such correlations with those derived from the 20 years of ERA-interim data. For four segments of such $6 \mathrm{yr}$ data segment that we examined, all yield correlations clustering around the correlations com- puted from the 20 -year data, with difference less than $\sim \pm 10 \%$ between $400-150 \mathrm{mb}$.

[18] All four GCMs examined here exhibit consistently higher correlation between UTH and SST anomalies than shown by the AIRS data and reanalyses products over all levels from $400 \mathrm{mb}$ to $150 \mathrm{mb}$. The correlations between the mean SST and UTH anomalies are as high as $\sim 0.88$ 0.95 . When rainy-region SST is used, the correlation is even higher for three GCMs with improvements of up to $\sim 5 \%$.

[19] To illustrate the contrast between model and observation in a more explicit way, Figure 3a shows scatter plots of ERA-interim humidity anomalies at $300 \mathrm{mb}$ versus SST (or rainy-region SST) anomalies and Figure 3b show the counterpart from the GFDL model output. For SST anomalies less than $0.2 \mathrm{~K}$, the spread of mean SST is only slightly wider than that of rainy-region SST. But for large positive anomalies $(>0.2 \mathrm{~K})$, the spread of mean SST is
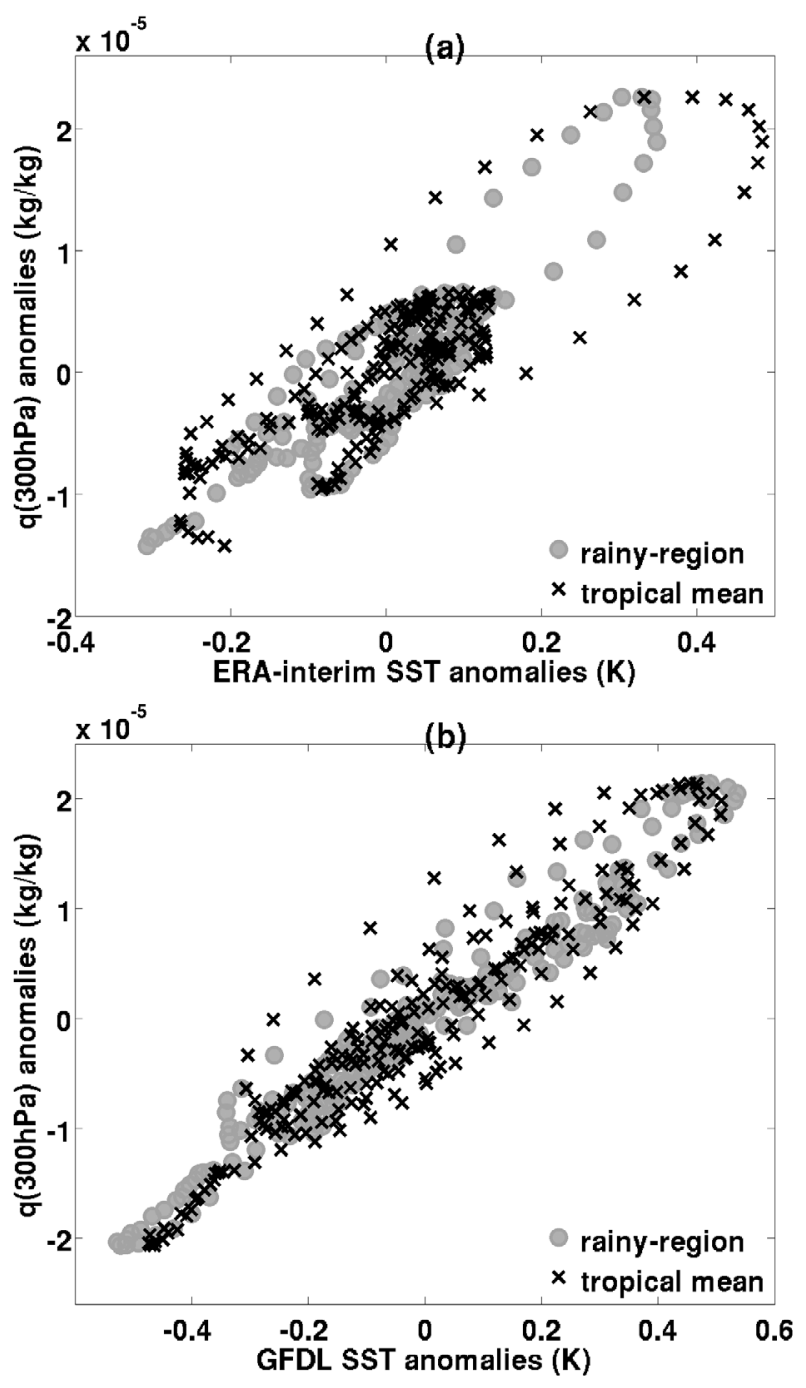

Figure 3. (a) Scatter plot of ERA-interim humidity anomalies at $300 \mathrm{mb}$ versus SST anomalies. The black crosses denote the inner-tropical mean SST anomalies, and the gray circles denote the rainy-region SST anomalies. (b) Same as Figure 3a except for the GFDL CM2.0 simulation. 

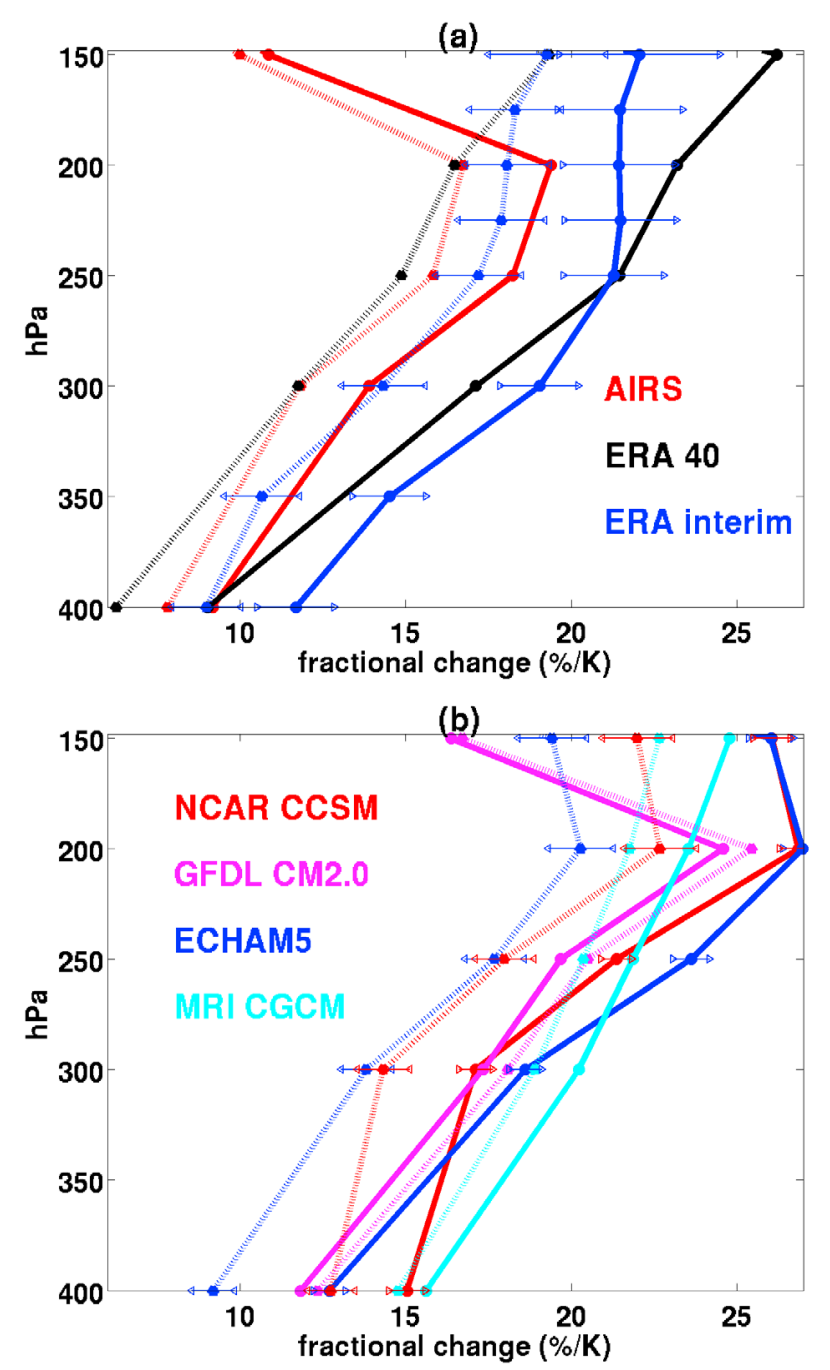

Figure 4. (a) Dotted (solid) lines are fractional change of specific humidity anomalies with respect to the innertropical-mean SST (rainy-region SST) anomalies. Only statistically significant results (i.e., $p$-value $<0.05$ ) are plotted. AIRS results show in red, ERA-40 in black, and ERAinterim in blue. The horizontal thin blue lines represent the $95 \%$ confident intervals of the regressed fractional change of the ERA-interim data. (b) Same as Figure 4a except for modeled fractional change. Different colors represent different GCMs as labeled on the plot. The $95 \%$ confident intervals for the ECHAM5 and NCAR CCSM models are plotted in horizontal thin lines.

substantially wider than that of rainy-region SST. This is consistent with what Sobel et al. [2002] described about the deviation between SST and rainy-region SST anomalies when the SST anomalies become large during an El Nino phase. It is such differences over the large positive SST anomalies that lead to the improved correlations shown in Figure 2a. In contrast, the GFDL CM2 (Figure 3b) does not exhibit such distinctive changes in terms of the spread of scatter plots when SST anomalies are large and positive. This behavior is consistent among all GCMs studied (not shown here), thus the difference between scatter plot of SST anomalies and that of rainy-region SST anomalies are insignificant over the entire range. Figure 4 shows the corresponding UTH anomalies $\left(\mathrm{q}_{\mathrm{a}}\right)$ regressed onto the SST anomalies $\left(\mathrm{SST}_{\mathrm{a}}\right)$ to obtain a fractional change of UTH with respect to SST anomalies, i.e., $\frac{1}{\bar{q}} \frac{d q_{a}}{d S S T_{a}}$ where $\bar{q}$ is the mean humidity. For both AIRS and the two reanalyses (Figure 4a), the fractional changes at all levels are larger when rainyregion SST is used instead of mean SST. For ERA-interim, the $95 \%$ confidence levels of fractional changes do not overlap each other from $400 \mathrm{mb}$ to $200 \mathrm{mb}$, indicating that the improvement is statistically significant. As for the GCM simulations (Figure $4 \mathrm{~b}$ ), the regression of fractional change is larger for all levels when rainy-region SST anomalies are used instead of mean SST anomalies for three GCMs. The improvements for NCAR CCSM and ECHAM5 are statistically significant at more than the $95 \%$ confidence level. GFDL model shows a slight decrease in regressed fractional change at all levels when rainy-regions SST is used, but all decreases here are statistically insignificant.

[20] Referring to Figures $2 \mathrm{a}$ and $2 \mathrm{~b}$, the significant differences in modeled and observed correlation coefficients between UTH and mean SST anomalies were noted by Sun and Held [1996]. Such model-observation discrepancies in correlation are substantially reduced here when AIRS or ERA-interim are used. Although the ERA-interim and ERA-40 have large disagreements on the correlations (Figure 2a), the regressed fractional changes of UTH for the two reanalyses are in fact in much better agreement (Figure 4a). This indicates that the low correlations between ERA-40 UTH and SST (mean or rainy-region) might be a result of relatively "noisy" UTH interannual anomalies in the ERA-40. ERA-interim, on the other hand, has improved moist physics and more refined methods to assimilate multiple years of HIRS $\mathrm{H}_{2} \mathrm{O}$ band radiances. These new features seemingly provide an improved capability for ERA-interim to represent the interannual anomalies of UTH.

[21] When rainy-region SST anomalies are used instead of mean SST anomalies, both AIRS and ERA-interim show changes in the correlations between UTH anomalies and SST anomalies, but the sign of such changes is not the same through all vertical levels. For AIRS, there is no improvement in correlation between 200 and $150 \mathrm{mb}$ (Figure 2a); note that $200 \mathrm{mb}$ is also the level where the maximum fractional change in UTH anomaly is attained (Figure 4a). Below this level, the AIRS fractional change in UTH anomalies is decreasing quickly from $19.4 \%$ to $9.2 \%$ at $400 \mathrm{mb}$. For ERA-interim, the improvement of correlation stops at $250 \mathrm{mb}$. Similar to the case of AIRS, $250 \mathrm{mb}$ is also the level below which the fractional change of ERA-interim UTH anomalies decreases quickly and above which the fractional change essentially levels off (Figure 4a). The results suggest that $200 \mathrm{mb}(250 \mathrm{mb})$ could be the level at which moisture anomalies have been influenced most by year-to-year variations in deep convection as seen from AIRS (ERA-interim), presumably via corresponding variations of the level of maximum detrainment since it is near this level where deep convection injects most saturated air into the upper troposphere. Previous studies suggest that the mean maximum outflow level from tropical deep convection 


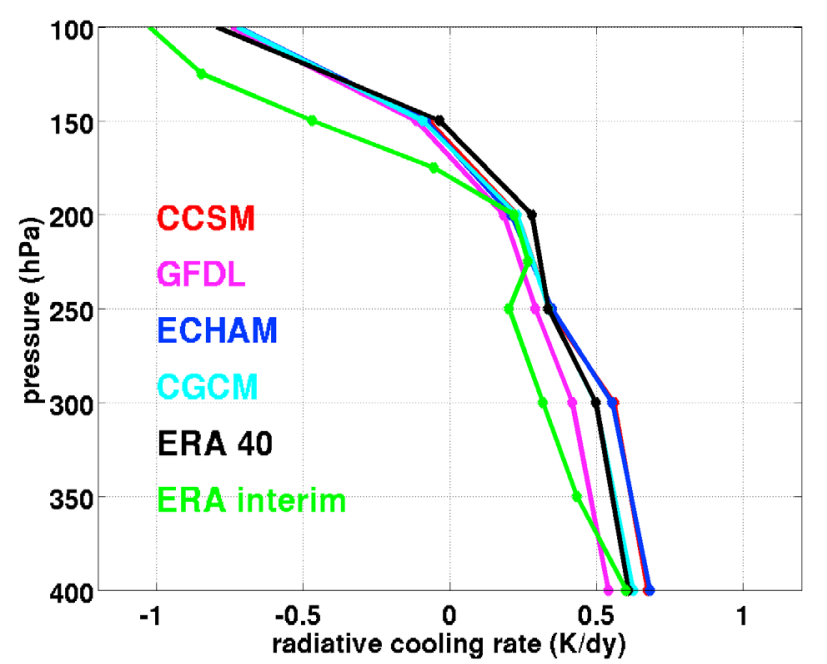

Figure 5. The 20 year-averaged radiative cooling rate (K/d) profile in the upper troposphere. Different colors represent different datasets as labeled on the plot. Note that the radiative cooling rate is signed positive for cooling.

is around $200 \mathrm{mb}(\sim 350 \mathrm{~K}$ in potential temperature $)$ [Folkins et al., 2000; Folkins, 2002; Fueglistaler et al., 2009] with certain geographical variations. For example, Thompson et al. [1979] suggested that it is about $13 \mathrm{~km}$ in the western Pacific and $11 \mathrm{~km}$ in the eastern Atlantic. Our findings here suggest that, if we are able to compile a probability distribution function (PDF) of maximum outflow level of tropical deep convection, the largest interannual variation of such PDF is likely concentrated around $200 \mathrm{mb}$ for AIRS but equally spread around $150-250 \mathrm{mb}$ for the ERA-interim reanalysis. All GCMs, except MRI CGCM, also show such a "turning point" at $200 \mathrm{mb}$ in terms of the fractional change of UTH anomalies with rainy-region SST anomalies.

\section{Results From an Idealized Model}

[22] In this section we explore the relations between simulated and observed UTH anomalies and deep convection from the perspective of an idealized model described in section 2. Figure 5 displays the tropical climatology of clear-sky net radiative cooling rates of four GCMs and two reanalysis datasets. The level of zero radiative cooling, for all cases, resides between $150 \mathrm{mb}$ and $200 \mathrm{mb}$. This level is assumed to be the highest level of convective detrainment in the idealized model. As in MD04, the humidity profile $\left(q_{D C}\right)$ is iteratively obtained from the equations (1)-(3) for a detrainment layer about $100 \mathrm{mb}$ in thickness below the level of zero radiative cooling (i.e., $200-300 \mathrm{mb}$ in this study). Therefore, below we will focus solely on this layer.

[23] Multiple-year means of the ratio of $q_{D C}$ to the humidity in GCM simulations (or reanalysis) is shown in Figure $6 \mathrm{a}$, accompanied by the yearly time series of such ratios at $250 \mathrm{mb}$ in Figure 6b. At the top part of the detrainment layer $(\sim 200 \mathrm{mb})$, the ratio varies from 1.5 to 2.1 with a median value of 1.74. In the middle and lower levels
(250-300 mb), the ratios for all GCMs and ERA-interim are clustered around 1.0 with a median value of 0.99 for $250 \mathrm{mb}$ and 0.94 for $300 \mathrm{mb}$. All GCMs and ERA-interim have small year-to-year variations. This corroborates that the contribution from deep-convective detrainment dominates the humidity variations at $250-300 \mathrm{mb}$ [Folkins et al., 2002] in these GCMs and the ERA-interim reanalysis, but that other mechanisms (especially drying mechanisms) are not negligible at $200 \mathrm{mb}$. The ERA-40 is an exception with a ratio of $\sim 1.2$ for $250 \mathrm{mb}$ and $300 \mathrm{mb}$ layers and 2.1 for $200 \mathrm{mb}$, largest among all models and reanalyses examined here. When the annual-mean time series of such ratios are examined (Figure 6b), it becomes clear that ERA-40 has a distinctly elevated ratio $\sim 1.4$ between 1989 and 1994. Given the fact that ERA-40 assimilated HIRS $6.7 \mu \mathrm{m}$ radiances directly and that the NOAA-11 HIRS radiance record is over the time frame from October 1988 to July 1994, this elevated ratio in ERA-40 might be related to how the HIRS on NOAA-11 has been assimilated, in addition to
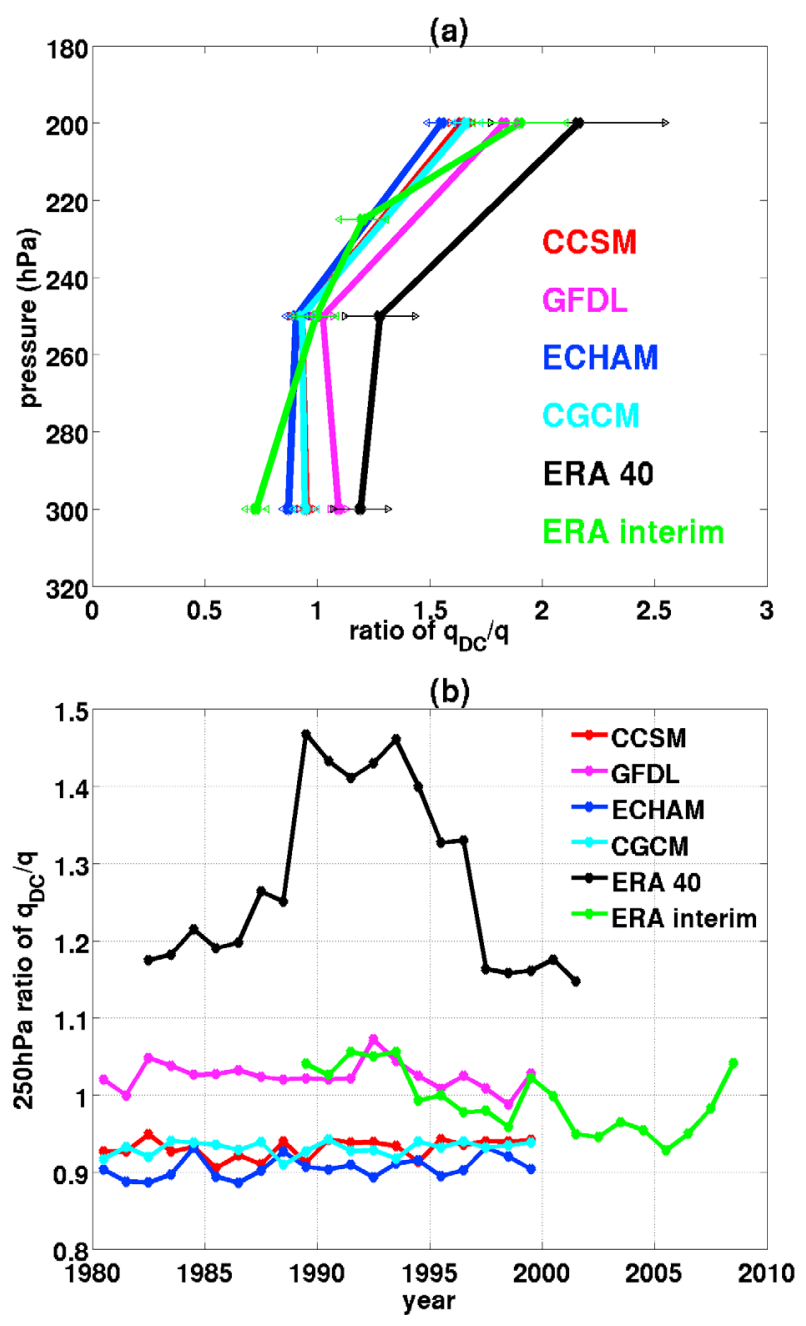

Figure 6. (a) The ratio of 20-year mean $\mathrm{q}_{\mathrm{DC}}$ to 20 -year mean specific humidity from GCM simulations (or ERA reanalysis datasets). The horizontal lines present one standard deviation. (b) The time series of yearly mean ratio of $\mathrm{q}_{\mathrm{DC}} / \mathrm{q}$ at $250 \mathrm{mb}$. Different colors represent different datasets as labeled on the plot. 
any possible contamination of Mt. Pinatubo eruption on the HIRS water vapor channels [Uppala et al., 2004; Uppala et al., 2005].

\section{Conclusion and Discussion}

[24] The relations between tropical mean UTH anomalies and the inner tropical SST anomalies over the interannual timescale are studied here with two reanalysis datasets from ECMWF, AIRS retrievals, and GCM simulations. The mean correlation between interannual anomalies of UTH and rainy-region SST is $0.4615,0.8611$, and 0.8721 for the ECMWF ERA-40, ERA-interim, and AIRS dataset, respectively. For AIRS and ERA-interim, when rainyregion SST anomalies are used instead of mean SST anomalies, it introduces discernible increases in the correlation with UTH between 400 and $150 \mathrm{mb}$ (though the increase for the AIRS result is within the estimated uncertainty due to its short time period). All four GCMs examined here consistently show significantly higher correlation coefficients between UTH anomalies and mean SST (rainyregion SST) anomalies (between 0.88 to 0.95 ). For AIRS observations and the two ECMWF reanalysis datasets, the fractional changes $\left(\frac{1}{\bar{q}} \frac{d q_{a}}{d S S T_{a}}\right)$ at all levels are larger when rainy-region SST anomalies are used instead of the mean SST anomalies. As for the GCM simulations, three of the four GCMs studied show larger fractional changes when rainy-region SST anomalies are used. When GCM or reanalysis temperature fields are fed into an idealized model with deep convection being the only source of tropical UTH, the specific humidity at $200 \mathrm{mb}$ (near the top of the mean detrainment layer) calculated by this idealized model is almost twice as humid as it in the reanalysis and GCMs. This indicates that other drying effects (e.g., mixing, extra-tropical air intrusion, etc.) might be equally important for the humidity variations in this level. Between 250 and $300 \mathrm{mb}$ (the lower part of convective detrainment layer), the specific humidity from this idealized model agrees relatively well with those from GCM and reanalyses, suggesting a more dominant control of the deep convection over other processes. The detrainment layer of deep convection has a finite vertical thickness. One implication here is that the competition between deep convection and other mechanisms for regulating UTH might vary significantly within such vertical ranges of the detrainment layer.

[25] Another finding of this study is the higher correlation between surface temperature and UTH anomalies in the ECMWF ERA-interim reanalysis compared to previous results from the ERA-40 reanalysis. A good agreement between the ERA-interim reanalysis and AIRS observations is also demonstrated. All reanalyses, based on algorithms originally designed for the variational analysis in numerical weather prediction, are aimed at achieving an optimal compromise between observation and modeling at each time step. To what extent such products can faithfully represent the climate aspect (e.g., annual-mean, interannual anomalies, decadal trends) of certain fields less constrained by observations cannot be easily quantified. The improvements made to ERA-interim reanalysis, on both the model physics and the quality control of radiances to be assimilated into the reanalysis, seemingly contribute to the better agreements between ERA-interim and AIRS, at least for the tropical UTH interannual variability.

[26] Because of the exponential dependence of saturation pressure on temperature, the saturation water vapor pressure could change by a factor of 10 or even more from the bottom part to the top part of the detrainment layer for tropical deep convection systems. Therefore, a reasonable representation of vertical detrainment profiles and its relation with large-scale circulation features, at least in a statistical sense, is vital to success in simulating the moistening of upper troposphere. If the moist convection scheme in a GCM puts water vapor at a wrong altitude in a wrong amount, it then gives following dynamic transport an incorrect starting point. Current GCMs tend to exhibit a prominent wet bias in the simulated UT specific humidity climatology when compared to observations. By comparing coupled-GCM simulations archived for the IPCC 4th Assessment Report with tropical UTH retrieved from AIRS observations, Pierce et al. [2006] and John and Soden [2007] both showed large moist bias $(25 \%-100 \%$ in the former and $100 \%$ and even more in the latter studies) in the free troposphere virtually for all GCMs that they had examined. These studies indicate that some common defects among these models should be responsible for such bias. Moreover, John and Soden [2007] showed that modeled planetary boundary layers (PBLs) also have a dry bias compared to the AIRS. By directly using spectrally resolved radiances instead of retrieved UTH, Huang et al. [2006] reached the same conclusion about such contrast of moist and dry biases between the free troposphere and the PBL in the GFDL GCM-AM2. Huang et al. [2006] also showed the dependence of such moist bias on the dynamic regimes: a stronger large-scale upward motion is associated with a larger moist bias. Both John and Soden [2007] and Huang et al. [2006] suggested that vertical transport of moisture to the UT (presumably by deep convection since it dominates the vertical transport) should be related to the moist bias in the mean climatology. The study here focuses on interannual variability and finds that the connections between tropical UTH and SST in tropical deep convection regions as seen in GCMs, reanalysis, and AIRS observations are different, which reaffirms the prerequisite need of improving the treatment of deep convections in order to correct any UTH moist bias in GCMs.

[27] On the other hand, recent coordinated observations such as CloudSat and AIRS provide unprecedented opportunities to characterize the detrainment and outflow structures of convective systems over the entire tropics, as well as the associated moistening effect. Such multiple years of records from both instruments will be able to help us further understand discrepancies and issues discussed in this study.

[28] The monthly mean NOAA OI SST is used in this study primarily because of its long coverage since the 1980 s, which is desired for the analysis of ERA-40 and ERA-interim data. This SST dataset is based on both in situ measurements and AVHRR SST retrieval [Reynolds et al., 2002], the latter of which is limited by the overcast clouds and heavy precipitation. Note the SST used in this study is a large-scale SST (e.g., SST averaged over a $2^{\circ} \times 2.5^{\circ}$ grid box) and the subgrid variation of such SST is usually small. On the other hand, AVHRR has very high spatial resolution 
( $\sim 1.1 \mathrm{~km}$ for IR imageries) and is capable of utilizing clearsky gaps between cloud systems to obtain SST retrievals. A microwave-based SST retrieval such as TMI SST is less subject to the issue of overcast clouds and heavy precipitation [Bhat et al., 2004] and is capable of producing a daily SST map. The TMI SST has been available only since December 1997 and is unsuitable for our study, but in the future when the data record becomes long enough, it will be a better candidate for this type of analysis.

[29] This study focuses on the variation of tropical or inner-tropical mean upper tropospheric specific humidity since the mean specific humidity is linearly proportional to the total mass of water vapor, which in turn is mostly determined by the vertical transport of water vapor mass flux from the boundary layer by deep convection. Such mean specific humidity is often the variable used to characterize the zonally averaged moisture field and appropriate for simple idealized model. We do note here that the arithmetical mean is not enough for a complete understanding of water vapor effects on the climate. Sherwood et al. [2006] and Ryoo et al. [2009] showed departures from normal distribution for the tropical upper troposphere relative humidity, indicating the limited usage of the mean to characterize the PDF of tropical relative humidity. Such departures are important for the radiative impact of water vapor because of the highly nonlinear relation between UTH and OLR. Therefore, understanding how the PDF of the tropical UTH varies with surface variables or other dynamic factors is also an important aspect in terms of advancing our knowledge of water vapor feedback, which is the focus of our future work.

[30] Acknowledgments. We wish to thank Drs. Z. Johnny Luo, Hui $\mathrm{Su}$, and Jonathon Wright for valuable discussions and comments. We also thank the two anonymous reviewers for their thoughtful comments. AIRS data was obtained from NASA GSFC DAAC and ECMWF reanalyses from http://data.ecmwf.int/data/. GCM simulations were obtained from the WCRP CMIP3 Multimodel data archived at PCMDI, Lawrence Livermore National Laboratory. NOAA_OI_SST_V2 data was provided by the NOAA/OAR/ESRL PSD, Boulder, Colorado, USA, from http://www.esrl. noaa.gov/psd/. This study is partly supported by NSF ATM 0755310 awarded to University of Michigan.

\section{References}

Adler, R. F., et al. (2003), The version-2 global precipitation climatology project (GPCP) monthly precipitation analysis (1979-present), J. Hydrometeorol., 4, 1147-1167.

Betts, A. K., and B. A. Albrecht (1987), Conserved Variable Analysis of the Convective Boundary-Layer Thermodynamic Structure over the Tropical Oceans, J. Atmos. Sci., 44, 83-99.

Bhat, G. S., et al. (2004), Sea surface temperature of the Bay of Bengal derived from the TRMM Microwave Imager, J. Atmos. Ocean. Technol., 21, 1283-1290.

Bony, S., et al. (2006), How well do we understand and evaluate climate change feedback processes?, J. Clim., 19, 3445-3482.

Camp, C. D., M. S. Roulston, and Y. L. Yung (2003), Temporal and spatial patterns of the interannual variability of total ozone in the tropics, J. Geophys. Res., 108(D20), 4643, doi:10.1029/2001JD001504.

Chen, J. Y., et al. (2008), The spatiotemporal structure of twentieth-century climate variations in observations and reanalyses. Part I: Long-term trend, J. Clim., 21, 2611-2633.

Dessler, A., and S. Sherwood (2000), Simulations of tropical upper tropospheric humidity, J. Geophys. Res., 105(D15), 20,155-20,163.

Dessler, A. E., Z. Zhang, and P. Yang (2008), Water-vapor climate feedback inferred from climate fluctuations, 2003-2008, Geophys. Res. Lett., 35, L20704, doi:10.1029/2008GL035333.

Fetzer, E. J., B. H. Lambrigtsen, A. Eldering, H. H. Aumann, and M. T. Chahine (2006), Biases in total precipitable water vapor climatologies from Atmospheric Infrared Sounder and Advanced Microwave Scanning Radiometer, J. Geophys. Res., 111, D09S16, doi:10.1029/ 2005JD006598.

Folkins, I. (2002), Origin of lapse rate changes in the upper tropical troposphere, J. Atmos. Sci., 59, 992-1005.

Folkins, I., S. J. Oltmans, and A. M. Thompson (2000), Tropical convective outflow and near surface equivalent potential temperatures, Geophys. Res. Lett., 27(16), 2549-2552.

Folkins, I., K. K. Kelly, and E. M. Weinstock (2002), A simple explanation for the increase in relative humidity between 11 and $14 \mathrm{~km}$ in the tropics, J. Geophys. Res., 107(D23), 4736, doi:10.1029/2002JD002185.

Fueglistaler, S., A. E. Dessler, T. J. Dunkerton, I. Folkins, Q. Fu, and P. W. Mote (2009), Tropical tropopause layer, Rev. Geophys., 47, RG1004, doi:10.1029/2008RG000267.

Hartmann, D. L., and M. L. Michelsen (2002), Comment on "No evidence for iris" - Reply, Bull. Am. Meteorol. Soc., 83, 1349-1352.

Held, I. M., and B. J. Soden (2000), Water vapor feedback and global warming, Ann. Rev. Energy. Environ., 25, 441-475.

Houze, R. A., Jr., and A. K. Betts (1981), Convection in GATE, Rev. Geophys., 19(4), 541-576.

Huang, X., B. J. Soden, and D. L. Jackson (2005), Interannual co-variability of tropical temperature and humidity: A comparison of model, reanalysis data and satellite observation, Geophys. Res. Lett., 32, L17808, doi:10.1029/2005GL023375.

Huang, X., V. Ramaswamy, and M. D. Schwarzkopf (2006), Quantification of the source of errors in AM2 simulated tropical clear-sky outgoing longwave radiation, J. Geophys. Res., 111, D14107, doi:10.1029/ 2005JD006576.

Huffman, G. J., et al. (2001), Global precipitation at one-degree daily resolution from multisatellite observations, J. Hydrometeorol., 2, 36-50.

Ingram, W. J. (2002), On the robustness of the water vapor feedback: GCM vertical resolution and formulation, J. Clim., 15, 917-921.

John, V. O., and B. J. Soden (2006), Does convectively-detrained cloud ice enhance water vapor feedback?, Geophys. Res. Lett., 33, L20701, doi:10.1029/2006GL027260.

John, V. O., and B. J. Soden (2007), Temperature and humidity biases in global climate models and their impact on climate feedbacks, Geophys. Res. Lett., 34, L18704, doi:10.1029/2007GL030429.

Kiehl, J. T., et al. (1998), The National Center for Atmospheric Research Community Climate Model: CCM3, J. Clim., 11, 1131-1149.

Kubota, T., and T. Terao (2004), Interdecadal variability of the seasonalscale persistence in the tropical mean tropospheric temperature, J. Meteorol. Soc. Jap., 82, 1213-1221.

Lindzen, R. S. (1990), Some Coolness Concerning Global Warming, Bull. Am. Meteorol. Soc., 71, 288-299.

Lindzen, R. S., et al. (2001), Does the earth have an adaptive infrared iris?, Bull. Am. Meteorol. Soc., 82, 417-432.

Minschwaner, K., and A. E. Dessler (2004), Water vapor feedback in the tropical upper troposphere: Model results and observations, J. Clim. 17, 1272-1282.

Moorthi, S., and M. J. Suarez (1992), Relaxed Arakawa-Schubert - a parameterization of moist convection for general-circulation models, Mon. Weather. Rev., 120, 978-1002.

Nordeng, T. E. (1994), Extended versions of the convective parameterization scheme at ECMWF and their impact on the mean and transient activity of the model in the tropics, Technical Memorandum No. 206, European Centre for Medium-Range Weather Forecasts, Reading, United Kingdom.

Pierce, D. W., T. P. Barnett, E. J. Fetzer, and P. J. Gleckler (2006), Threedimensional tropospheric water vapor in coupled climate models compared with observations from the AIRS satellite system, Geophys. Res. Lett., 33, L21701, doi:10.1029/2006GL027060.

Pierrehumbert, R. T. (1998), Lateral mixing as a source of subtropical water vapor, Geophys. Res. Lett., 25(2), 151-154.

Pierrehumbert, R. T., and R. Roca (1998), Evidence for control of Atlantic subtropical humidity by large scale advection, Geophys. Res. Lett., 25(24), 4537-4540.

Randall, D. A., and D.-M. Pan (1993), Implementation of the ArakawaSchubert cumulus parameterization with a prognostic closure, in Cumulus Parameterization, a Meteorological Monograph, American Meteorological Society, edited by K. Emanuel and D. Raymond, pp. 137-144.

Reynolds, R. W., and D. C. Marsico (1993), An Improved Real-Time Global Sea-Surface Temperature Analysis, J. Clim., 6, 114-119.

Reynolds, R. W., et al. (2002), An improved in situ and satellite SST analysis for climate, J. Clim., 15, 1609-1625.

Ryoo, J. M., et al. (2009), PDFs of Tropical Tropospheric Humidity: Measurements and Theory, J. Clim., 22, 3357-3373. 
Sherwood, S. C. (1996), Maintenance of the free-tropospheric tropical water vapor distribution. 1. Clear regime budget, J. Clim., 9, 2903-2918.

Sherwood, S. C., and A. E. Dessler (2003), Convective mixing near the tropical tropopause: Insights from seasonal variations, J. Atmos. Sci., 60, 2674-2685.

Sherwood, S. C., et al. (2006), A distribution law for free-tropospheric relative humidity, J. Clim., 19, 6267-6277.

Sherwood, S. C., R. Roca, T. M. Weckwerth, and N. G. Andronova (2010), Tropospheric water vapor, convection, and climate, Rev. Geophys., 48, RG2001, doi:10.1029/2009RG000301.

Simmons, A., et al. (2006), ERA_Interim: New ECMWF reanalysis products from 1989 onwards, ECM $\bar{M} F$ Newsletter, 110, 25-35.

Sobel, A. H., et al. (2002), The ENSO signal in tropical tropospheric temperature, J. Clim., 15, 2702-2706.

Soden, B., and F. Bretherton (1994), Evaluation of water vapor distribution in general circulation models using satellite observations, J. Geophys. Res., 99(D1), 1187-1210.

Soden, B. J., and R. Fu (1995), A satellite analysis of deep convection, upper-tropospheric humidity, and the greenhouse-effect, J. Clim., 8, 2333-2351.

Soden, B. J., and I. M. Held (2006), An assessment of climate feedbacks in coupled ocean-atmosphere models, J. Clim., 19, 3354-3360.

Soden, B. J., et al. (2005), The radiative signature of upper tropospheric moistening, Science, 310, 841-844.

Stone, P. H., and J. H. Carlson (1979), Atmospheric Lapse Rate Regimes and Their Parameterization, J. Atmos. Sci., 36, 415-423.

Su, H., W. G. Read, J. H. Jiang, J. W. Waters, D. L. Wu, and E. J. Fetzer (2006), Enhanced positive water vapor feedback associated with tropical deep convection: New evidence from Aura MLS, Geophys. Res. Lett., 33, L05709, doi:10.1029/2005GL025505.

$\mathrm{Su}, \mathrm{H}$., et al. (2008), Variations of tropical upper tropospheric clouds with sea surface temperature and implications for radiative effects, J. Geophys. Res., 113, D10211, doi:10.1029/2007JD009624.

Sun, D. Z., and I. M. Held (1996), A comparison of modeled and observed relationships between interannual variations of water vapor and temperature, J. Clim., 9, 665-675.
Sun, D. Z., and R. S. Lindzen (1993), Distribution of Tropical Tropospheric Water-Vapor, J. Atmos. Sci., 50, 1643-1660.

Sun, D. Z., et al. (2001), Vertical correlations of water vapor in GCMs, Geophys. Res. Lett., 28, 259-262.

Tiedtke, M. (1989), A Comprehensive Mass Flux Scheme for Cumulus Parameterization in Large-Scale Models, Mon. Weather. Rev., 117, 1779-1800.

Thompson, R. M., et al. (1979), Structure and Properties of Synoptic-Scale Wave Disturbances in the Intertropical Convergence Zone of the Eastern Atlantic, J. Atmos. Sci., 36, 53-72.

Udelhofen, P., and D. Hartmann (1995), Influence of tropical cloud systems on the relative humidity in the upper troposphere, J. Geophys. Res., 100(D4), 7423-7440.

Uppala, S., et al. (2004), ERA-40: ECMWF's 45-year reanalysis of the global atmosphere and surface conditions 1957-2002, ECMWF Newsletter, 101, 2-21.

Uppala, S. M., et al. (2005), The ERA-40 re-analysis, Quart. J. Roy. Meteorol. Soc., 131, 2961-3012.

Uppala, S., et al. (2008), Towards a climate data assimilation system: Status update of ERA-Interim, ECMWF Newsletter, 115, 12-18.

Wallace, J. M. (1992), Effect of deep convection on the regulation of tropical sea-surface temperature, Nature, 357, 230-231.

Xie, P. P., et al. (2003), GPCP Pentad precipitation analyses: An experimental dataset based on gauge observations and satellite estimates, J. Clim., 16, 2197-2214.

Xu, K. M., and K. A. Emanuel (1989), Is the tropical atmosphere conditionally unstable, Mon. Weather. Rev., 117, 1471-1479.

Zhang, G. J., and N. A. McFarlane (1995), Sensitivity of climate simulations to the parameterization of cumulus convection in the Canadian climate center general-circulation model, Atmos. Ocean, 33, 407-446.

H. Chuang and X. Huang, Department of Atmospheric, Oceanic and Space Sciences, University of Michigan, 2455 Hayward St., Ann Arbor, MI 48109, USA. (xianglei@umich.edu)

K. Minschwaner, Department of Physics, New Mexico Institute of Mining and Technology, 801 Leroy Pl., Socorro, NM 87801, USA. 